\title{
Pancreaticopleural fistula in children with chronic pancreatitis: a case report and literature review
}

\author{
Jia-yu Zhang ${ }^{1}$, Zhao-hui Deng ${ }^{1}$ and Biao Gong ${ }^{2^{*}}$
}

\begin{abstract}
Background: Pancreaticopleural fistula (PPF) is a very rare and critical complication of pancreatitis in children. The majority of publications relevant to PPF are case reports. No pooled analyses of PPF cases are available. Little is known about the pathogenesis and optimal therapeutic schedule. The purpose of this study was to identify the pathogenesis and optimal therapeutic schedule of PPF in children.

Case presentation: The patient was a 13-year-old girl who suffered from intermittent chest tightness and dyspnea for more than 3 months; she was found to have chronic pancreatitis complicated by PPF. The genetic screening revealed SPINK1 mutation. She was treated with endoscopic retrograde cholangiopancreatography (ERCP) and endoscopic retrograde pancreatic drainage (ERPD); her symptoms improved dramatically after the procedures.

Conclusions: PPF is a rare pancreatic complication in children and causes significant pulmonary symptoms that can be misdiagnosed frequently. PPF in children is mainly associated with chronic pancreatitis (CP); therefore, we highlight the importance of genetic testing. Endoscopic treatment is recommended when conservative treatment is ineffective.
\end{abstract}

Keywords: Pancreaticopleural fistula, Chronic pancreatitis, Child, Case report

\section{Background}

Pancreaticopleural fistula (PPF) is a very rare critical complication of pancreatitis in children that may occur secondary to acute or chronic pancreatitis, external or iatrogenic pancreatic trauma, leading to a fistula connecting the pancreas and pleural cavity presented or direct extension of a pseudocyst occurs when pancreatic duct rupture or pseudocyst formation; this can cause massive recurrent pleural effusion through the diaphragmatic hiatus and the peridiaphragmatic lymphatic plexus [1]. PPF causes significant pulmonary symptoms; it is misdiagnosed frequently, leading to a prolonged hospitalization time. In contrast to adult chronic

\footnotetext{
* Correspondence: gongbiaoercp@163.com

2Department of Digestive Diseases, Shanghai Shuguang Hospital, Shanghai University of Chinese Medicine, Shanghai 201203, China

Full list of author information is available at the end of the article
}

pancreatitis (CP), wherein smoking and alcohol are important risk factors, genetic predisposition is a major cause of $\mathrm{CP}$ in children [2]. As significant differences were observed in the forward prognosis among the patients with and without mutations [3-7], it is important to definite the cause of PPF, and determine the risk factors of primary pancreatic disease for the long-term follow-up. At present, no pooled analyses of PPF cases are available. Little is known about the pathogenesis and optimal therapeutic schedule. Here we describe a case of PPF in a girl who suffered from chest tightness, dyspnea, and massive pleural effusion and was successfully treated through endoscopic procedures after failed conservative therapy. The objective of this report was to identify the pathogenesis and optimal therapeutic schedule of pancreaticopleural fistulas in children by reviewing relevant literature. 


\section{Case presentation}

A 13-year-old girl presented with intermittent chest tightness and dyspnea for 3 months. She was admitted to a local hospital twice. On her first admission, blood smear examination showed a significantly increased eosinophilic ratio, and the cysticercus antibody was weakly positive. Chest and abdomen computed tomography (CT) showed a little left pleural effusion, uneven density of pancreas, and pelvic effusion. She was treated with albendazole, but the girl failed to follow medical advice, she stopped taking medicine after 5 days. Ten days later, her chest tightness and dyspnea aggravated, so she was readmitted to the hospital, chest CT showed a large left pleural effusion with atelectasis. She was then treated with thoracic tube drainage and albendazole. After 2 weeks, her chest tightness and dyspnea improved. However, she still complained of intermittent chest tightness and dyspnea within 2 months after discharge and lost 5 $\mathrm{kg}$ in the last six months. To further clarify the cause, the girl was referred to our hospital. In fact, she was complaining of intermittent abdominal pain for more than 1 year; however, since the pain was not intense, her parents did not pay attention to the complaint. The patient did not have any bad habits, such as smoking or drinking, and she had no history of abdominal trauma and surgery and biliary and pancreatic diseases. Her parents, sister, and brother were all in good health.

The patient's height and weight were $165 \mathrm{~cm}$ and 36 $\mathrm{kg}$, respectively. Physical examination revealed decreased vocal fremitus and breath sounds and dullness to percussion on the left hemithorax. Other components of her physical examination were unremarkable. Serum revealed mildly elevated amylase levels of $193 \mathrm{IU} / \mathrm{L}$ and lipase levels of $536 \mathrm{IU} / \mathrm{L}$, whereas pleural fluid amylase was elevated with levels of $>2400 \mathrm{IU} / \mathrm{L}$. Chest $\mathrm{x}$-ray and thoracic CT scan confirmed massive left hydropneumothorax with atelectasis (Fig. 1). Abdominal CT scan showed a small low-density lesion at the distal pancreas, accompanied by a pancreatic pseudocyst and main pancreatic duct dilatation (Fig. 2). Subsequently, magnetic resonance cholangiopancreatography (MRCP) revealed an abnormal tubular structure extending from the pancreatic pseudocyst along the spine to the pleural cavity, which was considered as a fistulous tract (Fig. 3). Hence, due to the radiological appearance and elevated pleural fluid amylase, massive recurrent pleural effusion was thought to be secondary to PPF, which was a complication of chronic pancreatitis. The patient and her parents underwent genetic tests, which revealed that the SPINK1 gene had "splice site variation c.194+2T> c (heterozygosity)". The mother carried this site variation (heterozygosity), while her father had a normal genotype.

A pleural drain was maintained for the patient. For fasting conditions, total parenteral nutrition was followed, and somatostatin and ulinastatin were initiated for 12 days. However, she still complained of intermittent chest tightness; bloody fluid continued to flow out from the chest drainage tube. The patient then underwent an endoscopic retrograde cholangiopancreatography (ERCP) that showed segmental stenosis and dilatation of the pancreatic duct and a pseudocyst at the pancreatic body and tail (Fig. 4). Endoscopic retrograde pancreatic drainage was performed. Two days later, there was a relief of chest tightness, and pleural effusion was significantly reduced. Due to the intractable pneumothorax, erythromycin was injected into the pleural cavity to fix the pleura for 5 days. Thirty- seven days after ERCP, the pleural drain was removed, and the patient was discharged at hospital day 52. Chest x-ray and serum amylase of the patient was followed-up regularly for 5 months, eventually revealing normal results. Five months after discharge, abdominal CT showed that the pancreatic pseudocyst was completely cured. Another ERCP was performed, which showed segmental stenosis and dilatation of the pancreatic duct, and the pseudocyst disappeared; hence, nasopancreatic drainage was performed for 3 days after the pancreatic duct stent was removed.
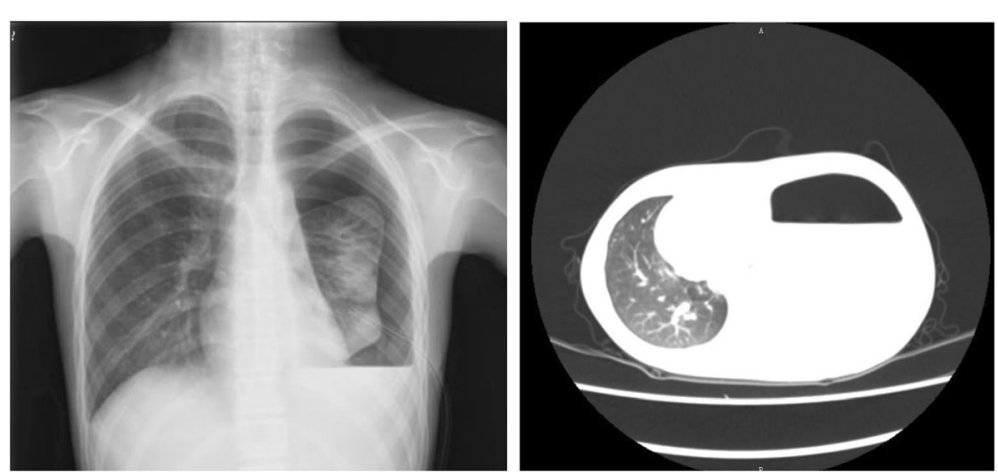

Fig. 1 An air-fluid level and atelectasis can be seen on the chest x-ray (left) and computed tomography (right) images, which showing massive left hydropneumothorax 


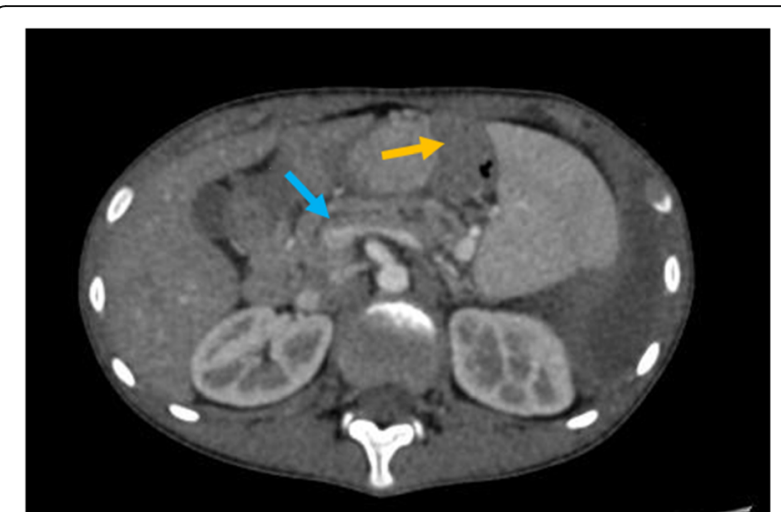

Fig. 2 Abdominal CT showed a small low-density lesion at the distal pancreas, accompanied by a dilatation of the main pancreatic duct (blue arrow) and the pancreatic pseudocyst (yellow arrow)

\section{Study identification and statistical analysis}

An extensive review of the literature was performed using the databases of PubMed, OVID, EMBASE, Medline, CNKI, and WANFANG, with keywords such as "pancreaticopleural fistula" and "child." We retrospectively analyzed 22 cases, including the current case and 21 additional patients derived from six Chinese articles and eight English articles (Table 1).

All available data were entered into a customized database and then analyzed by SPSS software version 23.0 (IBM Corp, Armonk, NY, USA), quantitative data were summarized as mean \pm standard deviation (SD) or number with percentage, where appropriate. Statistical analysis was performed using independent $\mathrm{t}$-test, one-way ANOVA test, and Tukey's post hoc test; statistical significance was defined as $P<0.05$.

The mean time to diagnose PPF was $2.69(0.25 \sim 6)$ months. Etiology analysis revealed 17 cases (77.3\%) of CP, 4 cases (18.2\%) of traumatic pancreatitis and one case (4.5\%) of suspected congenital ductal anomaly. In addition, 16 of 22 cases accompanied by a pancreatic pseudocyst. Among the 22 cases, 3 cases had complete genetic tests; one case revealed SPINK1 gene mutation, and one case revealed PRSS1 gene mutation. The main manifestations were dyspnea (15 cases, 68.2\%), abdominal pain (8 cases, 36.4\%), and thoracalgia (6 cases, 27.3\%). Except for three patients who were not clearly reported, amylase levels of the pleural effusion were significantly increased $(950 \sim 157,000 \mathrm{U} / \mathrm{L})$ in other patients. Seventeen cases (77.3\%) of fistula can be diagnosed by complementary imaging tests; among the 17 patients, only 9 cases (53\%) of fistula and its anatomy were identified through the esophageal hiatus (6 cases) and the aortic hiatus ( 3 cases) extending to the thoracic cavity. CT scan was performed in 14 cases, but fistulas were only found in 8 cases, with a sensitivity of $57.1 \%$; MRCP was performed in 9 cases, then 7 cases showed fistula, with a sensitivity of $77.8 \%$; ERCP was performed in 12 cases, of which 7 cases were therapeutic operations, and 5 cases were diagnostic operations, only 3 cases showed fistula, with a sensitivity of $25 \%$. Three cases $(13.6 \%)$ of fistula were confirmed during surgery; 2 cases (9.1\%) of fistula could not be demonstrated by imaging tests or surgical operation. Surgery alone was performed in four cases. Eighteen cases were first managed with conservative treatment; however, 14 cases needed endoscopic treatment $(7$ cases) or surgical intervention (7 cases) (Table 2).

Endoscopic treatment is a safe therapeutic option, among the 7 cases, only one case needed to reset a stent due to the pancreatic stent was removed spontaneously via defecation 8 days after stent insertion. However, one patient had empyema and bleeding after surgery. The efficacy of endoscopic treatment has also been proven; through endoscopic treatment, clinical symptoms and pleural effusion were improved significantly after $4 \pm 1.6$ days, compared with $5 \pm 2.8$ days after surgical intervention, there were no statistical differences; but compared with $17 \pm 4$ days after conservative treatment, statistical
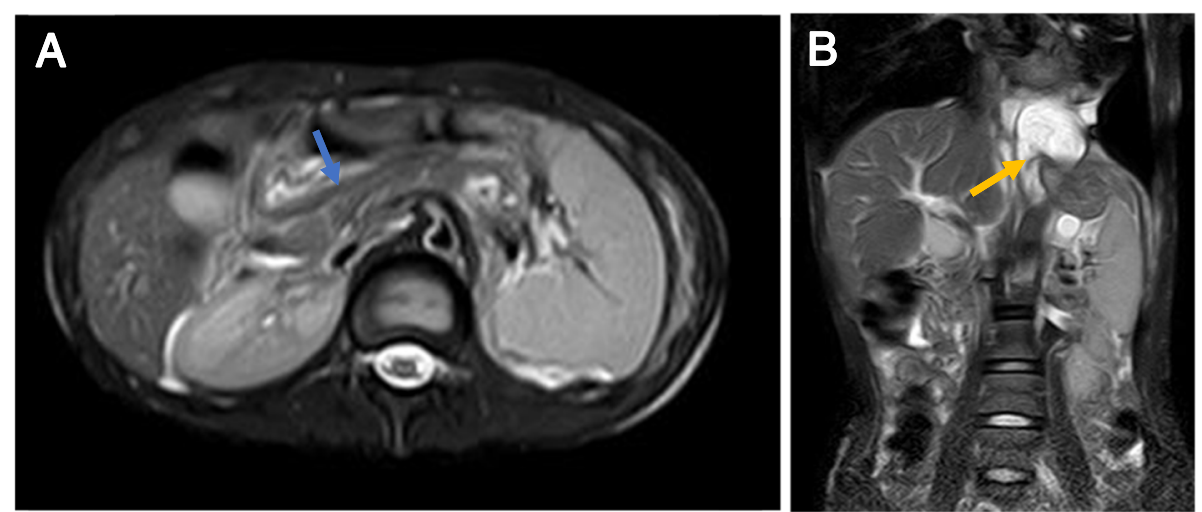

Fig. 3 a An MRCP revealed dilatation of the main pancreatic duct (blue arrow). b An MRCP revealed an abnormal tubular structure from the pancreatic pseudocyst to the pleural cavity (yellow arrow) 

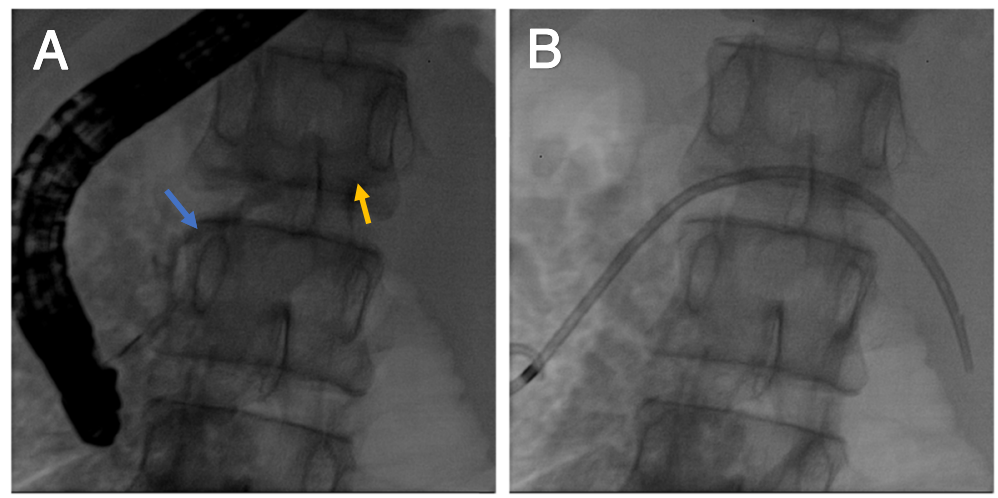

Fig. 4 a Endoscopic retrograde cholangiopancreatography (ERCP) showed segmental stenosis and dilatation of the pancreatic duct (blue arrow) and a pseudocyst at the pancreatic body and tail (yellow arrow). $\mathbf{b}$ ERCP showed a stent was placed into the pancreatic duct

differences could be $\operatorname{seen}(p=0.02)$. All patients improved and were discharged; the mean hospitalization time of endoscopic treatment was $34 \pm 17$ days, and conservative treatment was $50 \pm 12$ days, there were no statistical differences between the two groups. It's because endoscopic treatment was carried out after ineffective conservative treatment; the hospitalization time would have been prolonged. Patients treated by endoscopic treatment were in good health within three to fourteenmonths follow-up, and those treated by surgical

Table 1 Literature review of children with pancreaticopleural fistula

\begin{tabular}{|c|c|c|c|c|c|c|}
\hline Study & $\begin{array}{l}\text { N; age } \\
\text { (years)/ } \\
\text { Gender }\end{array}$ & Etiology & Genetic test & Main complaint & $\begin{array}{l}\text { Pleural fluid } \\
\text { amylase }^{\#}\end{array}$ & $\begin{array}{l}\text { Serum } \\
\text { amylase }^{\#}\end{array}$ \\
\hline $\begin{array}{l}\text { Ozbek et al. } \\
\text { [8] }\end{array}$ & $1 ; 5 / F$ & Trauma & None & Abdominal pain, dyspnea & 1200 & 334 \\
\hline $\begin{array}{l}\text { G Tanir et al. } \\
\text { [9] }\end{array}$ & $1 ; 12 / \mathrm{M}$ & Trauma & None & Thoracalgia, abdominal pain, dyspnea & - & 318 \\
\hline Lee et al. [10] & $1 ; 3.2 / \mathrm{M}$ & $C P$ & $\begin{array}{l}\text { PRSS1 gene } \\
\text { mutation }\end{array}$ & Abdominal pain, dyspnea & 25,460 & 888 \\
\hline $\begin{array}{l}\text { Duncan et al. } \\
\text { [11] }\end{array}$ & $2 ; 1.6 / \mathrm{M}, 10 / \mathrm{M}$ & $\mathrm{CP}$ & None & Dyspnea (2 cases), abdominal pain (1 case) & $\begin{array}{l}950 \\
157,000\end{array}$ & $\begin{array}{l}\text { Normal, } \\
\text { Not clear }\end{array}$ \\
\hline $\begin{array}{l}\text { Bishop et al. } \\
{[12]}\end{array}$ & $1 ; 4 / F$ & $\mathrm{CP}$ & Negative & Dyspnea, wheeze & 12,170 & 751 \\
\hline $\begin{array}{l}\text { Ranuh et al. } \\
\text { [13] }\end{array}$ & $1 ; 12 / \mathrm{M}$ & $C P$ & None & Abdominal pain, dyspnea & $40,000^{\&}$ & $1974^{\&}$ \\
\hline $\begin{array}{l}\text { Fitzgibbons } \\
\text { et al. [14] }\end{array}$ & $1 ; 16 / F$ & $\mathrm{CP}$ & None & Thoracalgia, abdominal pain, dyspnea & 45,666 & - \\
\hline $\begin{array}{l}\text { Wakefield } \\
\text { et al. [15] }\end{array}$ & $2 ; 3 / M, 4 / M$ & $\begin{array}{l}\text { ?Congenital } \\
\text { ductal anomaly }\end{array}$ & None & Abdominal pain in 2 cases, dyspnea in 1 case & $\begin{array}{l}9737 \\
>16,000\end{array}$ & 329,4935 \\
\hline $\begin{array}{l}\text { Zhuang LL } \\
\text { et al. [16] }\end{array}$ & $1 ; 14 / F$ & $C P$ & None & Cough, chest pain, dyspnea & $11,239.8$ & 566.6 \\
\hline $\begin{array}{l}\text { Liu XY et al. } \\
\text { [17] }\end{array}$ & $1 ; 14 / \mathrm{M}$ & $\mathrm{CP}$ & None & Cough, dyspnea & 26,110 & 1911 \\
\hline $\begin{array}{l}\text { Yu FH et al. } \\
\text { [18] }\end{array}$ & $\begin{array}{l}5 ; 2 \sim 10.4 / \\
M^{*} 3, F^{*} 2\end{array}$ & $\mathrm{CP}$ & None & $\begin{array}{l}\text { Chest tightness, chest pain, fever in } 3 \text { cases, wheezing, } \\
\text { dyspnea, abdominal pain in } 1 \text { case }\end{array}$ & $\begin{array}{l}1546 \sim 50 \\
465\end{array}$ & $110 \sim 889$ \\
\hline Li J et al. [19] & $1 ; 11 / F$ & $C P$ & None & Chest tightness & 4206 & 130 \\
\hline $\begin{array}{l}\text { Chen B et al. } \\
{[20]}\end{array}$ & 2;2/M,8/M & Trauma & None & $\begin{array}{l}\text { Fever in } 2 \text { cases, abdominal distension, cough, dyspnea } \\
\text { in } 1 \text { case }\end{array}$ & $>1300$ & $\begin{array}{l}\text { Not clear, } \\
5100\end{array}$ \\
\hline $\begin{array}{l}\text { Yu ZX et al. } \\
{[21]}\end{array}$ & $1 ; 8 / F$ & $\mathrm{CP}$ & None & Dyspnea & $56,365.7$ & 504.8 \\
\hline
\end{tabular}


Table 2 Baseline characteristics of children with pancreaticopleural fistula $(n=22)$

\begin{tabular}{|c|c|c|}
\hline & No & $\%$ \\
\hline \multicolumn{3}{|l|}{ Demographics } \\
\hline Male & 13 & 59.1 \\
\hline \multicolumn{3}{|l|}{ Etiology } \\
\hline $\mathrm{CP}$ & 17 & 77.3 \\
\hline traumatic & 4 & 18.2 \\
\hline ?Congenital ductal anomaly & 1 & 4.5 \\
\hline Accompanied by pancreatic pseudocyst & 16 & 72.7 \\
\hline \multicolumn{3}{|l|}{ Main manifestations } \\
\hline dyspnea & 15 & 68.2 \\
\hline abdominal pain & 8 & 36.4 \\
\hline thoracalgia & 6 & 27.3 \\
\hline \multicolumn{3}{|l|}{ Diagnosis of fistula } \\
\hline Imaging tests & 17 & 77.3 \\
\hline Surgery & 3 & 13.6 \\
\hline No fistula could be demonstrated & 2 & 9.1 \\
\hline Conservative treatment & 4 & 18.2 \\
\hline \multicolumn{3}{|l|}{ Endoscopic treatment } \\
\hline ERPD & 3 & 13.6 \\
\hline$E S T+E P B D$ & 1 & 4.5 \\
\hline ERPD+ Stone extraction & 1 & 4.5 \\
\hline EST+ Stone extraction+ ERPD & 1 & 4.5 \\
\hline Nasopancreatic drainage followed by stenting of the duct & 1 & 4.5 \\
\hline \multicolumn{3}{|l|}{ Surgery treatment } \\
\hline LPJ & 8 & 36.4 \\
\hline Internal drainage of pseudocysts and anastomosed to a Roux-en-Y loop of jejunum & 1 & 4.5 \\
\hline Partial pancreatectomy & 1 & 4.5 \\
\hline Partial pancreatectomy, pancreatolithotomy and LPJ & 1 & 4.5 \\
\hline
\end{tabular}

Note: EST Endoscopic sphincterotomy; ERPD Endoscopic Retrograde Pancreatic Drainage; EPBD Endoscopic Papilia-sphincter Balloon Dilatation; LPJ

Longitudinal pancreaticojejunostomy

intervention also remained healthy within eleven to twenty-four months follow-up. Unfortunately, the hospitalization time of surgical intervention and followup information about conservative treatment could not acquire from our review, so that no more analysis can be made.

\section{Discussion and conclusions}

PPF is a rare complication of pancreatitis. It is caused by acute or chronic pancreatitis, pancreatic trauma, or iatrogenic rupture of the pancreatic duct. Among the 22 cases of PPF, 17 cases (77.3\%) were secondary to chronic pancreatitis, indicating that chronic pancreatitis was the main cause of PPF in children. Adult CP is mainly due to acquired factors, such as alcohol and smoking. $\mathrm{CP}$ in children is mostly associated with gene mutation and abnormal structure of the biliopancreatic duct. Gene mutation is the main risk factor of $\mathrm{CP}$ in children. Previous research in children has shown that 33\% with acute pancreatitis (AP), $45.4 \%$ of acute recurrent pancreatitis (ARP), and $54.4 \%$ with $\mathrm{CP}$ have genetic susceptibility [22]. Xiao $Y$ et al. [23] found that the positive rates of pathogenic genes for CP and ARP in Chinese children were 71.1 and $47.1 \%$, respectively. In our review, three children with $\mathrm{CP}$ underwent genetic testing, and two of them revealed gene mutations. This indicates that children with CP may have genetic abnormalities that are closely related to the development of CP. Hereditary pancreatitis is a dominant inheritance with high penetrance, which may be complicated with pancreatic exocrine dysfunction (35-37\%), diabetes (26-32\%), and pancreatic cancer $(6 \%)$ in the future $[3,4]$. Mutationpositive patients had significantly earlier median ages at diagnosis of pancreatic stones, diabetes mellitus, and steatorrhea than mutation-negative CP patients [5]. In addition, children with mutation-positive reveal a 


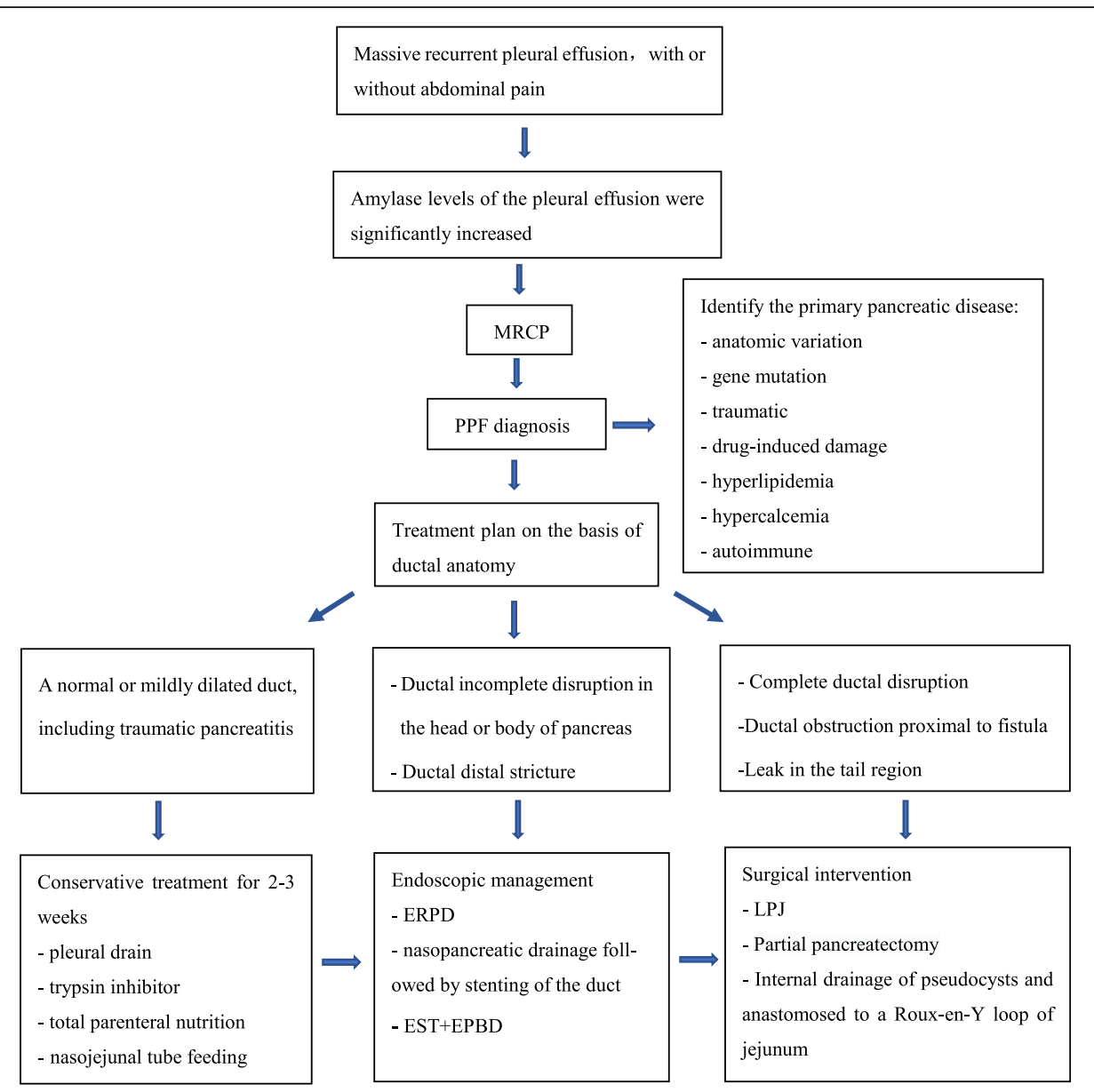

Fig. 5 Flowchart for the treatment strategy in children with pancreaticopleural fistula

significantly more severe clinical course of the disease and complications than mutation-negative children [6, 7]. Therefore, genetic testing has important significance for predicting prognosis and long-term management in children.

Currently identified pathogenic genes include serine protease inhibitor Kazal type 1 gene (SPINKI), cystic fibrosis transmembrane conductance regulator gene (CFTR), cationic trypsinogen protease serine 1 (PRSS1) gene, and the cystic fibrosis transmembrane conductance regulator gene (CTRC) gene [24]. The genetic basis of $\mathrm{CP}$ varies significantly according to age, race, and region $[25,26]$. The mutation rate of the PRSS1 gene in Chinese children with chronic pancreatitis is significantly higher than in adults. The IVS $3+2 \mathrm{TC}$ splice site mutation of SPINK1 is the most common gene mutation in Chinese children [18], while the N34S gene mutation of SPINK1 is most common in white patients [27-30]. In the present study, two patients revealed gene mutations; one case was reported in Korea, revealing an $\mathrm{R} 122 \mathrm{H}$ mutation of PRSS1 gene with a family history of pancreatic disease, and the other case is our patient with "splicing site variation c.194+2T> c (heterozygous)" mutation of SPINK1 gene.

Diagnosing PPF is not complex; it can be diagnosed through significantly elevated amylase in the pleural effusion and through abdominal imaging test. However, it can still be misdiagnosed frequently. The average time to diagnosis PPF is 5 weeks based on the previous study [31]. The main reason for misdiagnosing is that PPF is a rare disease, and the main manifestations are pulmonary symptoms caused by repeated pleural effusion, and abdominal symptoms are infrequent. Sometimes, serum amylase may not be increased, and the fistula can be difficult to demonstrate radiologically. In this study, 77.3\% of fistulas can be demonstrated radiologically; MRCP is the best imaging test to diagnose PPF with a sensitivity of $77.8 \%$, which is consistent with previous research [32], and no radiation. The anatomical relationship between the pancreatic duct and the fistula can also be demonstrated in detail, which is beneficial to determine therapy; CT scan can better reveal the pancreatic parenchyma with a sensitivity of $57.1 \%$. However, the sensitivity of ERCP to demonstrated PPF is $25 \%$, which is 
significantly lower than the previous study [33]. ERCP is superior to other modalities to show the pancreatic anatomy but will often fail to demonstrate the fistula, selective duct cannulation, or even an operative pancreatogram may be required in the presence of tight structure [34]. In our study, only 53\% of PPF and its anatomy were identified through imaging, which showed that imaging test is limited in revealing the anatomy of PPF. The main approaches of PPF to the mediastinum are aortic hiatus and esophageal hiatus. Imaging tests can show the diffusion pathway of the retroperitoneal space; however, it cannot show the relationship between the fascia plane, ligament, and retroperitoneal subspace clearly, which is the reason for the limitation of imaging test.

The treatment of PPF includes conservative treatment, endoscopic treatment, and surgical intervention. The treatment depends on the ductal anatomy. A normal or mildly dilated pancreatic duct, including traumatic pancreatitis, can be managed with conservative treatment, including pleural drain, trypsin inhibitor, nasojejunal tube feeding, and total parenteral nutrition. In $30-60 \%$ of cases, medical treatment is successful $[35,36]$. In the presence of ductal incomplete disruption in the head or body of pancreas and distal stricture, an endoscopic approach can be made initially using a stent, sphincterotomy, or balloon dilatation, which can reduce the pressure of the pancreatic duct. In $88 \%$ of cases, pancreatic duct fractures can heal [37], and $48 \%$ of fistulas can be closed within $2-3$ weeks $[38,39]$. If endoscopic treatment is not possible due to complete ductal disruption, ductal obstruction proximal to fistula, leak in the tail region, or unsuccessful management, surgery, such as partial pancreatectomy, longitudinal pancreaticojejunostomy (LPJ), or internal drainage of pseudocysts can be considered [33]. PPF is a rare complication in children; there are no relevant epidemiological studies to confirm which therapeutic method is the best. In the present study, 18 cases were treated with conservative treatment initially; however, only one case of $\mathrm{CP}$ and 3 cases of trauma pancreatitis with PPF could be managed successfully, the other 14 cases need endoscopic treatment and surgery intervention eventually, indicating that except for traumatic pancreatitis with PPF, the most PPF cannot be managed successfully with conservative treatment.

Surgical treatment for PPF mainly includes pancreatectomy and LPJ, but for the primary pancreatic disease, such as $\mathrm{CP}$, there is a high rate of pain recurrence after operation [40], sometimes even cause pancreatic insufficiency. Compared with surgery, endoscopic treatment has the advantages of being minimally invasive, quick recovery, fast transition to enteral nutrition, which can be repeated and significantly shortened hospitalized time $[41,42]$. Recently reported literature showed that endoscopic treatment for symptomatic $\mathrm{CP}$ in children is a safe and effective therapeutic option [43-45]. D Kohoutova et al. [46] recommend endoscopic treatment of $\mathrm{CP}$ in children before surgical operation based on their long-term follow-up. In this study, two cases of PPF with gene mutations were cured by endoscopic treatment. We found that endoscopic treatment was minimally invasive and effective. After placing a stent, pleural effusion was significantly reduced on the second day without any related complications, and the pancreatic tissue has no additional damages. During the fivemonths follow-up, she was in good health, symptomfree, and serum amylase level are within normal limits. Therefore, endoscopic treatment is recommended for PPF in children, especially for chronic pancreatitis. A flowchart for the optimal treatment strategy in children with PPF has been recommended (Fig. 5).

PPF is a rare pancreatic complication in children, which can be misdiagnosed frequently. It should be considered when a child presents with repeated massive pleural effusion. The etiology of PPF in children is mostly due to CP. Genetic testing should be carried out to identify gene mutations. Endoscopic treatment is minimally invasive, safe, and effective; therefore, it is recommended for children with PPF.

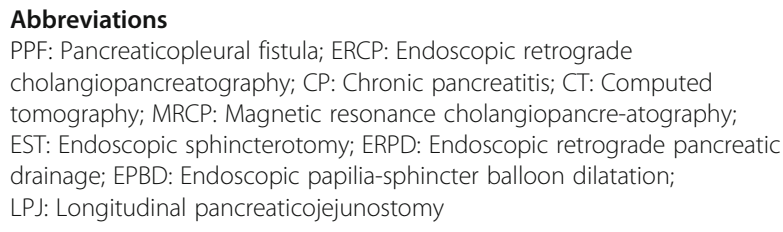

\section{Acknowledgments}

The authors would like to thank the patient and his family for their consent to publish this report.

\section{Authors' contributions}

JYZ and ZHD contributed equally to this article; JYZ drafted the manuscript and reviewed the literature; ZHD gathered information and revised the manuscript; BG treated the patient and made critical revisions related to the important intellectual content of the manuscript; all the authors have read and approved the final version to be published.

\section{Funding}

Supported by the Shanghai Municipal Health Bureau, No. ZY (2018-2020)FWTX-1105.

\section{Availability of data and materials}

The data presented in this article are available in the reference listed below.

\section{Ethics approval and consent to participate}

The case report was performed according to the Declaration of Helsinki. Written informed consent was obtained from the patient's parents for the publication of this case report and accompanying images.

\section{Consent for publication}

Written informed consent for publication of this case report and accompanying images was obtained from the parents of the patients.

Competing interests

All authors declare that they have no competing interests. 


\section{Author details}

'Department of Pediatric Digestive Diseases, Shanghai Children's Medical Center, Shanghai Jiao Tong University School of Medicine, Shanghai 200127, China. ${ }^{2}$ Department of Digestive Diseases, Shanghai Shuguang Hospital, Shanghai University of Chinese Medicine, Shanghai 201203, China.

Received: 5 March 2020 Accepted: 27 May 2020

Published online: 03 June 2020

\section{References}

1. Cazzo E, Apodaca-Rueda M, Gestic MA, Chaim FHM, Saito HPA, Utrini MP, et al. Management of pancreaticopleural fistulas secondary to chronic pancreatitis. ABCD Arq Bras Cir Dig. 2017;30:225-8.

2. Vue PM, McFann K, Narkewicz MR. Genetic mutations in pediatric pancreatitis. Pancreas. 2016:45:992-6.

3. Gariepy CE, Heyman MB, Lowe ME, Pohl JF, Werlin SL, Wilschanski M, et al. Causal evaluation of acute recurrent and chronic pancreatitis in children: consensus from the INSPPIRE group. J Pediatr Gastroenterol Nutr. 2017;64: 95-103.

4. Lee YJ, Cheon CK, Kim K, Oh SH, Park JH, Yoo HW. The PRSS1c.623G >C ( $p$. $\mathrm{G} 208 \mathrm{~A}$ ) mutation is the most common PRSS1 mutation in Korean children with hereditary pancreatitis. Gut. 2015;64:359-60.

5. Lee YJ, Kim KM, Choi JH, Lee BH, Kim GH, Yoo HW. High incidence of PRSS1 and SPINK1 mutations in Korean children with acute recurrent and chronic pancreatitis. J Pediatr Gastroenterol Nutr. 2011;52:478-81.

6. Chandak GR, Idris MM, Reddy DN, Mani KR, Bhaskar S, Rao GV, et al. Absence of PRSS1 mutations and association of SPINK1 trypsin inhibitor mutations in hereditary and non-hereditary chronic pancreatitis. Gut. 2004; 53:723-8.

7. RH PF, Barmada MM, Brunskill AP, Finch R, Hart PS, Neoptolemos J, et al. SPINK1/PSTI polymorphisms act as disease modifiers in familial and idiopathic chronic pancreatitis. Gastroenterology. 2000;119:615-23.

8. Seda Ozbek, Meltem Gumus, Hasan Ali Yuksekkaya, Batur A. An unexpected cause of pleural effusion in paediatric emergency medicine. BMJ Case Rep. 2013; 16:. pii: bcr2013009072

9. Tanir G, Kansu A, Dogru U, Girgin N, Gözdaşoglu S, Oztekin C. An unusual cause of recurrent pleural effusion in a child. Pancreas. 1999:18:212-8.

10. Lee D, Lee EJ, Kim JW, Moon JS, Kim YT, Ko JS. Endoscopic management of pancreaticopleural fistula in a child with hereditary pancreatitis. Pediatr Gastroenterol Hepatol Nutr. 2019;22:601-7.

11. Duncan ND, Ramphal PS, Dundas SE, Gandreti NK, Robinson-Bridgewater LA, Plummer JM. Pancreaticopleural fistula: a rare thoracic complication of pancreatic duct disruption. J Pediatr Surg. 2006;41:580-2.

12. Bishop JR, Mcclean P, Davison SM, Sheridan MB, Zamvar V, Humphrey G, et al. Pancreaticopleural fistula: a rare cause of massive pleural effusion. J Pediatr Gastroenterol Nutr. 2003:36:134-7.

13. Ranuh R, Ditchfield M, Clarnette T, Auldist A, Oliver MR. Surgical management of a pancreaticopleural fistula in a child with chronic pancreatitis. J Pediatr Surg. 2005;40:1810-2.

14. Fitzgibbons RJ Jr, Nugent FW, Ellis FH Jr, Braasch JW, Scholz FJ. Unusual thoracoabdominal duplication associated with pancreaticopleural fistula. Gastroenterology. 1980;79:344-7.

15. Wakefield S, Tutty B, Britton J. Pancreaticopleural fistula: a rare complication of chronic pancreatitis. Postgrad Med J. 1996;72:115-6.

16. Zhuang LL, Gong HH. Pancreaticopleural fistula: a case report and literature. Jiangsu Med J. 2018;44:973-6.

17. Liu XY, Li YL. Pleural effusion caused by chronic pancreaticopleural fistula: a case report. J Clin Intern Med. 2019;36:172-3.

18. Yu FH, Xu XW, Zhang J, Yang HM, Zhou J, Wang GL. Analysis of pancreaticopleural fistula in 5 children. Chin J Appl Clin Pediatr. 2015;30:1344-6.

19. Li J, Zou YZ, Guo YS, Liu J, Xi J. Rare etiology of pleural effusion in children: report of 2 cases. Chin J Pract Pediatr. 2017;32:239-40.

20. Chen B, Mao J, Chen JM, Xiong S, Xu X. Imaging features in two children be diagnosed as pancreaticopleural fistulas with massive pleural effusion. Chin J Radiol. 2014;48:606-7.

21. Yu ZX, Yu YP, Huang XZ. Massive hemorrhagic pleural effusion caused by pancreaticopleural fistula in children: a case report and literature. J Clin Pediatr. 2019:37:427-31.

22. Poddar U, Yachha SK, Mathias A, Choudhuri G. Genetic predisposition and its impact on natural history of idiopathic acute and acute recurrent pancreatitis in children. Dig Liver Dis. 2015;47:709-14.
23. Xiao Y, Yuan WT, Yu B, Guo Y, Xu X, Wang XQ, et al. Target ed gene nextgeneration sequencing in chinese children with chronic pancreatitis and acute recurrent pancreatitis. J Pediatr. 2017;191:158-163.e3.

24. Howes N, Lerch MM, Greenhalf W, Stocken DD, Ellis I, Simon P, et al. Clinical and genetic characteristics of hereditary pancreatitis in Europe. Clin Gastroenterol Hepatol. 2004;2:252-61.

25. Ebours V, Boutron-Ruault M-C, Schnee M, Férec C, Le Maréchal C, Hentic O, et al. The natural history of hereditary pancreatitis:a national series. Gut. 2009:58:97-103.

26. Zou WB, Tang XY, Zhou DZ, Qian YY, Hu LH, Yu FF, et al. SPINK1, PRSS1, CTRC, and CFTR genotypes influence disease onset and clinical outcomes in chronic pancreatitis. Clin Transl Gastroenterol. 2018;9:204

27. Oracz G, Kolodziejczyk E, Sobczynska-Tomaszewska A, Wejnarska K, Dadalski M, Alicja Grabarczyk AM, et al. The clinical course of hereditary pancreatitis in children- a comprehensive analysis of 41 cases. Pancreatology. 2016;16: 535-41.

28. Konzen K, Perrault J, Moir C, Zinsmeister A. Long-term follow-up of young patients with chronic hereditary or idiopathic pancreatitis. Mayo Clin Proc 1993:68:449-53.

29. Schneider A, Suman A, Rossi L, Barmada MM, Beglinger C, Parvin S, et al. SPINK1/PSTI mutations are associated with tropical pancreatitis and type ॥ diabetes mellitus in Bangladesh. Gastroenterology. 2002;123:1026-30.

30. Gomez-Lira M, Bonamini D, Castellani C, Unis L, Cavallini G, Assael BM, et al. Mutations in the SPINK1 gene in idiopathic pancreatitis Italian patients. Eur J Hum Genet. 2003;11:543-6.

31. Tay CM, Change SK. Diagnosis and management of pancreaticopleural fistula. Singapore Medical J. 2013;54:190-4.

32. Aswani Y, Hira P. Pancreaticopleural fistula: a review. Pancreas. 2015;16:90-4.

33. Wronski M, Slodkowski M, Cebulski W, Moronczyk D, Krasnodebski LW. Optimizing management of pancreaticopleural fistulas. World J Gastroenterol. 2011:17:4696-703.

34. Williams SG, Bhupalan A, Zureikat N, Thuluvath PJ, Santis G, Theodorou N, et al. Pleural effusions associated with Pancreaticopleural fistula. Thorax. 1993:48:867-83

35. Ali T, Srinivasan N, Le V, Chimpiri AR, Tierney WM. Pancreaticopleural fistula. Pancreas. 2009;38:e26-31.

36. Rockey DC, Cello JP. Pancreaticopleural fistula. Report of 7 patients and review of literature. Medicine (Baltimore). 1990;69:332-44.

37. Neher JR, Brady PG, Pinkas H, Ramos M. Pancreaticopleural fistula in chronic pancreatitis: resolution with endoscopic therapy. Gastrointest Endosc. 2000; 52:416-8.

38. Dhebri AR, Ferran N. Nonsurgical management of pancreaticopleural fistula. JOP. 2005;6:152-61.

39. Altasan T, Aljehani Y, Almalki A, Algamdi S, Talag A, Alkattan K. Pancreaticopleural fistula: an overlooked entity. Asian Cardiovasc Thorac Ann. 2014:22:98-101.

40. Andersen DK, Frey CF. The evolution of the surgical treatment of chronic pancreatitis. Ann Surg. 2010;251:18-32.

41. King JC, Reber HA, Shiraga S, Hines OJ. Pancreatic pleural fistula is best managed by early operative intervention. Surg. 2010;147:154-9.

42. Li ZS, Wang W, Liao Z, Zou DW, Jin ZD, Chen J, et al. A long-term follow-up study on endoscopic management of children and adolescents with chronic pancreatitis. Am J Gastroenterol. 2010;105:1884-92.

43. Agarwal J, Nageshwar Reddy D, Talukdar R, Lakhtakia S, Ramchandani M,

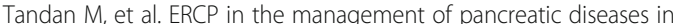
children. Gastrointest Endosc. 2014;79:271-8.

44. Felux J, Sturm E, Busch A, Zerabruck E, Graepler F, Stüker D, et al. ERCP in infants, children and adolescents is feasible and safe: results from a tertiary care center. United European Gastroenterol J. 2017:5:1024-9.

45. Kohoutova D, Tringali A, Papparella G, Perri V, Boškoski I, Hamanaka J, et al. Endoscopic retrograde cholangiopancreatography in the pediatric population is safe and efficacious. J Pediatr Gastroenterol Nutr. 2013;57:649-54.

46. Kohoutova D, Tringali A, Papparella G, Perri V, Boškoski I, Hamanaka J, et al. Endoscopic treatment of chronic pancreatitis in pediatric population Longterm efficacy and safety. United Eur Gastroenterol J. 2019;7:270-7.

\section{Publisher's Note}

Springer Nature remains neutral with regard to jurisdictional claims in published maps and institutional affiliations. 